\title{
O impacto financeiro da rastreabilidade em sistemas de produção de bovinos no Estado de Santa Catarina, Brasil
}

\author{
Financial impact of tracking systems in the bovine production in the State of Santa Catarina, Brazil
}

\author{
Ricardo Evandro Mendes ${ }^{1}$
}

\section{RESUMO}

Este trabalho teve por objetivo analisar o impacto financeiro da implantação de um sistema de rastreabilidade bovina, utilizando brincos plásticos duplos, nas propriedades rurais do Estado de Santa Catarina. Utilizaram-se os dados do Levantamento Agropecuário Catarinense (LAC), o qual identificou, em $1^{\text {o }}$ de setembro de 2003, uma média de 22,8 bovinos por propriedade. O custo apurado para a implantação de um sistema de rastreabilidade nas propriedades rurais do Estado com 23 bovinos, para o primeiro ano, variou entre $R \$$ 19,20 e R\$24,76/animal. Já para o segundo ano, este valor aumenta, variando entre $R \$ 33,64$ e $R \$ 36,81 /$ animal. Concluiu-se que, devido ao elevado valor para a implantação da rastreabilidade, é inviável a sua adoção no Estado de Santa Catarina. Isto se deve principalmente à grande maioria das pequenas propriedades rurais Catarinenses serem caracterizadas por minifúndios, com um pequeno número de animais.

Palavras-chave: rastreabilidade, bovinos, custo de implantação, Santa Catarina.

\section{ABSTRACT}

This study was aimed at evaluating the financial cost impact over the bovine production in the rural properties of the State of Santa Catarina, Brazil, after establishment of a track system through double plastics earrings. Based on demographic data from the Levantamento Agropecuário Catarinense (LAC), a mean of 22.8 bovine per property was calculated in September 1st, 2003. The costs for establishment of a track system for 23 bovines were calculated, being from $R \$$ 19.20 to $R \$ 24.76$ for the first year and from $R \$ 33.64$ to $R \$$ 36.81 for the second year per animal. In conclusion, the adoption of a track system may be jeopardized in the State of Santa Catarina, mainly due to the elevated cost and the fact that most of the properties are considered as small-lands, with a low number of animals per property.
Key words: tracking system, bovines, financial costs, State of Santa Catarina.

\section{INTRODUÇÃO}

A rastreabilidade tem como objetivo garantir ao consumidor um produto seguro e saudável por meio do controle de todas as fases da produção, industrialização, transporte/distribuição e comercialização, possibilitando uma perfeita correlação entre o produto final e a matéria-prima que lhe deu origem (MACHADO \& NANTES, 2000a).

A união européia, baseada nos princípios de equivalência, está exigindo que todos os países que exportem para aquele mercado, como o Brasil, adotem um sistema de identificação e registro de animais, além de um sistema de rotulagem com garantia de rastreabilidade, de acordo com a legislação que está em vigor para todos os países comunitários. Com respeito à segurança alimentar, a rastreabilidade do sistema de produção de carnes é uma garantia dada ao consumidor europeu, pela legislação comunitária, que lhe dá a certeza de estar consumindo um produto que está sendo controlado em todas as fases da produção - desde a fazenda até a mesa do consumidor (LOMBARDI, 2000).

O Brasil possui o maior rebanho bovino comercial do mundo, sendo o maior exportador de carne. Este bom desempenho no mercado externo depende, basicamente, do atendimento às exigências dos principais mercados compradores, como os países da União Européia.

${ }^{1}$ Universidade do Estado de Santa Catarina (UDESC). Av. Luiz de Camões, 2090, 88520-000, Lages, SC, Brasil. E-mail: a2rem@cav.udesc.br. Autor para correspondência. 
Com a globalização e a criação dos blocos econômicos, o sistema produtor de alimentos deve estar preparado para a inserção de seus produtos em um mercado altamente exigente. Por isso, a importância em se garantir a qualidade e a segurança dos alimentos aos consumidores surgiu como questão estratégica para a indústria, varejo e para os órgãos públicos, principalmente para os países exportadores (MACHADO \& NANTES, 2000b).

O episódio do aparecimento da Encefalopatia Espongiforme Bovina (BSE) foi considerado o motivador do surgimento do conceito de rastreabilidade nos produtos cárneos. A possibilidade de contaminação dos consumidores europeus levou os agentes públicos e privados a se organizarem não só para erradicar a enfermidade, como também para impedir sua disseminação para os humanos, tendo assim a rastreabilidade um importante papel no controle epidemiológico da doença (WILLIAMSON, 1999).

A implantação do Sistema Brasileiro de Identificação e Certificação de Origem Bovina e Bubalina-SISBOV-contribuirá decisivamente para o aumento das exportações de produtos cárneos e para a conquista de novos mercados. Este sistema se resume em um conjunto de ações, medidas e procedimentos adotados para caracterizar a origem, o estado sanitário, a produção e a produtividade da pecuária nacional e a segurança dos alimentos provenientes dessa exploração econômica. O objetivo do sistema é identificar, registrar e monitorar, individualmente, todos os bovinos e bubalinos nascidos no Brasil ou importados (BRASIL, 2002).

Considerando que a maioria dos estabelecimentos agropecuários do Estado compõese por minifúndios e que estes não detêm capital nem condições técnicas para a implantação de um sistema de rastreabilidade, este trabalho tem por objetivo fazer uma análise de custo da implantação de um sistema de rastreabilidade, associando esta à realidade da bovinocultura no Estado de Santa Catarina.

\section{MATERIAL E MÉTODOS}

O presente trabalho-se constitui de uma simulação com estudos de casos relacionados com a implantação de um sistema de rastreabilidade bovina em sistemas de produção de bovinos com 11, 23 e 55 animais, no Estado de Santa Catarina, dando ênfase maior ao impacto financeiro que a sua implantação traria aos pequenos produtores rurais. Optou-se por estas quantidades por representarem a média dos efetivos menores, médios e maiores, respectivamente, nos estabelecimentos agropecuários das diferentes microrregiões do Estado de Santa Catarina (ICEPA, 2004).

Foi estimado o custo para a implantação de um sistema de rastreabilidade utilizando brincos duplos de plástico em pequenas propriedades do Estado de Santa Catarina por duas empresas certificadoras. Os valores foram obtidos através do site das respectivas empresas. Os valores da visita técnica foram estimados através de média entre no mínimo dois técnicos credenciados para tal serviço pelas empresas. Estes se localizavam normalmente na cidade principal das mesorregiões do Estado, e foram estabelecidos por meio do valor médio que vinham cobrando para este serviço dentro desta região.

$\mathrm{O}$ valor da mão-de-obra é relativo às despesas com a implantação na propriedade do processo de rastreamento bovino, sendo de $\mathrm{R} \$ 50,00$ para o primeiro ano e de R \$ 15,00 para o segundo ano de implantação do sistema. Estes valores são uma estimativa de todos os custos operacionais para a implantação de um sistema de rastreabilidade, como, por exemplo, o pagamento de possíveis ajudantes para a brincagem e manejo dos animais, possíveis despesas para contato e contratação da empresa certificadora, despesas para a aquisição dos brincos e outros materiais necessários ao processo. Como estes valores são muito variáveis de uma propriedade para outra, estabeleceu-se como padrão os especificados acima, como uma estimativa.

Os dados do número de animais nas propriedades e do número de propriedades do Estado são provenientes do Levantamento Agropecuário Catarinense e correspondem à data de $1^{0}$ de setembro de 2003. Nessa ocasião, a população média de bovinos por propriedade aproximava-se de 22,8 cabeças, nos 140.887 estabelecimentos agropecuários. A maior concentração média encontrava-se na região de Curitibanos, com 55,7 animais por propriedade, e a menor em Araranguá, no Sul do Estado, com 11,3 bovinos por propriedade (ICEPA, 2004).

Os valores citados acima para a implantação e execução do sistema são referentes a outubro de 2004.

\section{RESULTADOS E DISCUSSÃO}

Nas tabelas 1 a 3, são apresentados os custos da implantação de um sistema de rastreabilidade por duas empresas certificadoras para efetuar a rastreabilidade de 11, 23 e 55 animais em uma propriedade. Os custos estão expressos em reais, tanto nos valores individuais como no valor total.

O valor encontrado por animal para efetuar a rastreabilidade em uma propriedade com 11 animais (Tabela 1) variou entre R\$35,56 e R\$ 48,47. Em uma propriedade rural com 23 animais (Tabela 2), o valor 
Tabela 1 - Valor da rastreabilidade (R\$) para uma propriedade com 11 animais.

\begin{tabular}{lcc}
\hline Item & Empresa A & Empresa B \\
\hline Anuidade & $\mathrm{NC}^{1}$ & 100,00 \\
Taxa de credenciamento & 45,00 & 100,00 \\
Taxa referente aos animais $^{2}$ & 12,10 & 11,00 \\
Brincos $^{3}$ & 34,10 & 22,22 \\
Mão-de-obra & 50,00 & 50,00 \\
Visita do técnico & 250,00 & 250,00 \\
Valor final para a propriedade (R\$) & 391,20 & 533,22 \\
Valor por animal (R\$) & 35,56 & 48,47 \\
\hline
\end{tabular}

${ }^{1}$ Valor não cobrado por esta empresa.

${ }^{2}$ Taxa unitária por animal de R 1,10 e R \$ 1,00 para a empresa A e B, respectivamente.

${ }^{3}$ Valor unitário dos brincos de R\$ 3,10 e R\$ 2,02 para a empresa A e $\mathrm{B}$, respectivamente.

variou entre R\$19,20 e R\$ 24,76. Já numa propriedade rural com 55 animais (Tabela 3), o valor variou entre $R \$$ 10,47 e R\$12,11.

O custo/animal encontrado neste trabalho para as propriedades com 55 animais (Tabela 3) está um pouco acima do encontrado por SARTO (2002) para 50 animais por propriedade, sendo em média $\mathrm{R} \$ 8,38$ por animal, variando entre $\mathrm{R} \$$ 5,00/animal e $\mathrm{R} \$ 9,75 /$ animal. Isto pode ser ocasionado por uma pequena elevação nos preços devido à inflação durante os dois anos que separam estes trabalhos ou, até mesmo, a outras variações regionais.

Atualmente, os frigoríficos do Estado que necessitam de bovinos rastreados pagam um adicional de R \$1,00 por arroba rastreada. Assim, em um bovino de $450 \mathrm{~kg}$, o produtor recebe um adicional de R\$15,00 a cada animal rastreado abatido. Os técnicos ligados ao

Tabela 2 - Valor da rastreabilidade (R\$) para uma propriedade com 23 animais.

\begin{tabular}{lcc}
\hline Item & Empresa A & Empresa B \\
\hline Anuidade & $\mathrm{NC}^{1}$ & 100,00 \\
Taxa de credenciamento & 45,00 & 100,00 \\
Taxa referente aos animais $^{2}$ & 25,30 & 23,00 \\
Brincos $^{3}$ & 71,30 & 46,46 \\
Mão-de-obra & 50,00 & 50,00 \\
Visita do técnico & 250,00 & 250,00 \\
Valor final para a propriedade (R\$) & 441,60 & 569,46 \\
Valor por animal (R\$) & 19,20 & 24,76 \\
\hline
\end{tabular}

${ }^{1}$ Valor não cobrado por esta empresa.

${ }^{2}$ Taxa unitária por animal de $\mathrm{R} \$ 1,10$ e $\mathrm{R} \$ 1,00$ para as empresas A e $\mathrm{B}$, respectivamente.

${ }^{3}$ Valor unitário dos brincos de R\$ 3,10 e R\$ 2,02 para as empresas A e $\mathrm{B}$, respectivamente. setor da rastreabilidade acreditam que a tendência é este valor aumentar, a partir do momento em que começarem a faltar animais rastreados para que sejam oferecidos ao mercado. Mas a maioria dos frigoríficos, que são de pequeno e médio porte, não pagam este adicional, pois não necessitam de um animal rastreado até o momento.

O custo para 23 animais ficou entre $\mathrm{R} \$ 19,20$ e R \$24,76 por animal (Tabela 2). Este valor inviabiliza a adoção da rastreabilidade para a maioria das propriedades rurais do Estado de Santa Catarina, pois, subtraindo o custo da rastreabilidade do valor adicional que pode ser obtido com ela junto ao frigorífico ( $\mathrm{R} \$$ $15,00)$, o resultado é negativo $(\mathrm{R} \$ 15,00-\mathrm{R} \$ 19,20=\mathrm{R} \$$ $-4,20)$, resultando em uma relação custo-benefício negativa. Quando se toma por base as propriedades com 11 animais, a situação é ainda pior ( R \$ 15,00 - R\$ 35,56 = R \$-20,56).

Para propriedades maiores, com 55 animais, como pode ser observado na tabela 3 , os custos da rastreabilidade são menores que a receita obtida com o adicional pago pelo frigorífico ao bovino rastreado ( $\mathrm{R} \$$ $15,00-10,47=R \$ 4,53)$, sendo o resultado positivo. Neste caso, o produtor rural tem um incentivo para optar pela implantação do sistema sem muitos problemas. Entretanto, propriedades com este número de animais não são a realidade do Estado, pois somente uma pequena parcela das propriedades se encaixa neste perfil.

Deve-se levar em conta também que inicialmente o produtor deverá cadastrar e rastrear todos os animais de sua propriedade e, nos anos seguintes, somente os animais nascidos. Como o número de animais nascidos é pequeno, em torno de $40 \%$ do plantel, a taxa de visita do veterinário terá um rateio menor, encarecendo ainda mais o valor por animal rastreado. Na tabela 4 , foi calculado o valor da

Tabela 3 - Valor da rastreabilidade (R\$) para uma propriedade com 55 animais.

\begin{tabular}{lcc}
\hline Item & Empresa A & Empresa B \\
\hline Anuidade & $\mathrm{NC}^{1}$ & 100,00 \\
Taxa de credenciamento & 45,00 & 100,00 \\
Taxa referente aos animais $^{2}$ & 60,50 & 55,00 \\
Brincos $^{3}$ & 170,50 & 111.10 \\
Mão-de-obra & 50,00 & 50,00 \\
Visita do técnico & 250,00 & 250,00 \\
Valor final para a propriedade (R\$) & 576,00 & 666,10 \\
Valor por animal (R\$) & 10,47 & 12,11 \\
\hline
\end{tabular}

${ }^{1}$ Valor não cobrado por esta empresa.

${ }^{2}$ Taxa unitária por animal de R\$ 1,10 e R\$ 1,00 para as empresas A e $\mathrm{B}$, respectivamente.

${ }^{3}$ Valor unitário dos brincos de R \$ 3,10 e R \$ 2,02 para as empresas A e $B$, respectivamente.

Ciência Rural, v.36, n.5, set-out, 2006. 
Tabela 4 - Valor da rastreabilidade (R\$) para o segundo ano em uma propriedade com 23 animais.

\begin{tabular}{lcc}
\hline Item & Empresa A & Empresa B \\
\hline Anuidade & $\mathrm{NC}^{1}$ & 100,00 \\
Taxa referente aos animais $^{2}$ & 9,90 & 9,00 \\
Brincos $^{3}$ & 27,90 & 18,18 \\
Mão-de-obra & 15,00 & 15,00 \\
Visita do técnico & 250,00 & 250,00 \\
Valor final para a propriedade (R\$) & 302,80 & 392,18 \\
Valor por animal (R\$) & 33,64 & 36,81 \\
\hline
\end{tabular}

${ }^{1}$ Valor não cobrado por esta empresa.

${ }^{2}$ Taxa unitária por animal de $\mathrm{R} \$ 1,10$ e $\mathrm{R} \$ 1,00$ para as empresas A e $\mathrm{B}$, respectivamente.

${ }^{3}$ Valor unitário dos brincos de R \$ 3,10 e R \$ 2,02 para as empresas A e $\mathrm{B}$, respectivamente.

rastreabilidade para a propriedade, no segundo ano do processo, com um plantel de 23 cabeças (média de animais por propriedade do Estado, contendo: 10 matrizes (vacas), com o nascimento de 9 bezerros ao ano e o descarte de 6 animais para o abate). Para o cálculo, não foi incluída a taxa de inscrição, pois esta é paga somente uma vez no início do processo, e os valores dos brincos e da taxa por animal são para os nove animais, ou seja, os animais nascidos que serão brincados pela primeira vez. A taxa de mão-de-obra reduziu-se a $\mathrm{R} \$ 15,00$ devido ao menor número de animais (nove) que serão brincados.

O valor final para a continuidade do processo de rastreabilidade para o segundo ano reduzse, em comparação com os valores da tabela 2, referentes ao primeiro ano. Mas deve-se lembrar que serão brincados apenas nove animais (os nascidos). Para a empresa A, se este valor total for rateado entre os nove animais que serão brincados $(302,80 \div 9$ ), obtém-se o valor individual (por animal) de R\$ 33,64. Para a empresa B, levando em conta que a anuidade deve ser rateada entre todos os animais da propriedade $(\{292,18 \div 9\}+\{100 \div 23\})$, obtém-se o valor individual (por animal) de R $\$ 36,81$. Portanto, o valor total em relação ao primeiro ano é menor, mas o valor individual (por animal) aumenta consideravelmente de R \$ 19,20/ cabeça para R\$33,64/cabeça, no caso da empresa A. Nesta perspectiva, os gastos com a continuidade do processo de rastreabilidade aumentam consideravelmente.

Na tabela 5, foi calculado o custo total da implantação do sistema de rastreabilidade pelas duas empresas, para os dois primeiros anos, em uma propriedade com 23 animais, a qual é a média de animais por propriedade do Estado de Santa Catarina (ICEPA, 2004). São apresentados os valores para o primeiro (Ano 1) e o segundo ano (Ano 2) da implantação do sistema de rastreabilidade (Tabela 2 e 4, respectivamente), sendo então estes somados individualmente e apresentados nas duas últimas colunas da direita (Total A e B).

Conforme os dados do Levantamento Agropecuário Catarinense (ICEPA, 2004), há no Estado de Santa Catarina 3.216.543 cabeças de bovinos, distribuídos em inúmeras propriedades. Calculandose um valor médio entre R \$ 19,20 e R \$ 24,76 (Tabela 2) por animal, obtém-se o custo médio para rastrear uma cabeça animal no Estado, que é de R \$ 21,98. Este valor, multiplicado pelo total de bovinos do Estado, fornece a cifra de R\$70.699.615,14. Portanto, o valor a ser desembolsado pelos produtores rurais para realizar a completa rastreabilidade dos bovinos no Estado de Santa Catarina é muito elevado, já que o Produto Interno Bruto (PIB) do setor do Agronegócio Catarinense em 2002 foi de R\$5.852.561,00 (IBGE, 2002).

Tabela 5 - Valor da rastreabilidade (R\$) para os dois primeiros anos em uma propriedade com 23 animais.

\begin{tabular}{|c|c|c|c|c|c|c|}
\hline \multirow{2}{*}{ Item } & \multicolumn{2}{|c|}{ Ano 1} & \multicolumn{2}{|c|}{ Ano 2} & \multirow{2}{*}{ Total A } & \multirow{2}{*}{ Total B } \\
\hline & Empresa A & Empresa B & Empresa A & Empresa B & & \\
\hline Anuidade & $\mathrm{NC}^{1}$ & 100,00 & $\mathrm{NC}^{1}$ & 100,00 & $\mathrm{NC}^{1}$ & 200,00 \\
\hline Taxa de credenciamento & 45,00 & 100,00 & $\mathrm{NC}^{2}$ & $\mathrm{NC}^{2}$ & 45,00 & 100,00 \\
\hline Taxa referente aos animais ${ }^{3}$ & 25,30 & 23,00 & 9,90 & 9,00 & 35,20 & 32,00 \\
\hline Brincos $^{4}$ & 71,30 & 46,46 & 27,90 & 18,18 & 99,20 & 64,64 \\
\hline Mão-de-obra & 50,00 & 50,00 & 15,00 & 15,00 & 65,00 & 65,00 \\
\hline Visita do técnico & 250,00 & 250,00 & 250,00 & 250,00 & 500,00 & 500,00 \\
\hline Valor por propriedade (R\$) & 441,60 & 569,46 & 302,80 & 392,18 & 744,40 & 961,64 \\
\hline
\end{tabular}

${ }^{1}$ Valor não cobrado por esta empresa.

${ }^{2}$ Valor cobrado somente no primeiro ano.

${ }^{3}$ Taxa unitária por animal de R 1,10 e R\$ 1,00 para as empresas A e B, respectivamente.

${ }^{4}$ Valor unitário dos brincos de R\$ 3,10 e R \$ 2,02 para as empresas A e B, respectivamente.

Ciência Rural, v.36, n.5, set-out, 2006. 
Vale lembrar que este valor cobre os gastos com o primeiro ano da implantação; após isso, será acrescido dos animais que nascerem. Estimando este número de animais nascidos em $40 \%$ do plantel (3.216.543 animais), obtém-se o número de 1.286.617 animais nascidos e que terão que ser brincados, a um custo médio de R\$33,64/animal (Tabela 4), resultando em um desembolso de R $\$ 40.281 .795$ para os produtores do Estado de Santa Catarina no segundo ano da implantação da rastreabilidade em todas as propriedades rurais simultaneamente. Este montante sairá do capital das pequenas propriedades catarinenses e, na sua grande maioria, não retornará a estas, descapitalizando-as, visto que o valor adicional nos custos é superior ao adicional na receita.

O valor do gasto para o Estado de Santa Catarina para os dois primeiros anos da implantação da rastreabilidade pode ser calculado também a partir dos dados da tabela 5 , em que se obtém uma média de gasto por propriedade para os dois primeiros anos de $\mathrm{R} \$ 853,02(\{961,64+744,40\} \div 2)$. Este valor, multiplicado pelo número de propriedades do Estado (140.887) (ICEPA, 2004), resulta em um valor de R $\$ 120.179 .428,74$.

\section{CONCLUSÃO}

O alto custo operacional da rastreabilidade nas pequenas propriedades do Estado inviabiliza a implantação do sistema. Tal fato poderá contribuir para a exclusão destes produtores rurais da comercialização de bovinos futuramente. Se não for criada uma forma alternativa para a implantação da rastreabilidade bovina no Estado, por meio da criação de associações ou cooperativas que diluam o custo da anuidade, a taxa de inscrição e o valor cobrado pelo técnico, muitos produtores rurais ficarão à margem do processo. Especula-se a possibilidade de a Companhia Integrada de Desenvolvimento Agrícola de Santa Catarina (CIDASC), órgão do Governo do Estado, executar os procedimentos necessários à implantação da rastreabilidade nas propriedades. Porém, isto poderá vir a sobrecarregar o quadro de funcionários desta instituição. Entretanto, pelo elevado custo levantado, pode ser mais vantajoso à economia do Estado de Santa Catarina arcar com os custos da rastreabilidade com dinheiro público do que descapitalizar os produtores rurais, mas isto deve ser avaliado por um estudo técnico e econômico muito bem conduzidos pelo setor público.

Uma solução mais econômica poderia ser efetivada com a contratação dos serviços de um técnico por uma cooperativa regional ou municipal, o qual visitaria e cadastraria os animais das propriedades, fazendo uma ligação entre a certificadora e o produtor rural a um custo menor. Outra possibilidade seria, uma negociação com a empresa para reduzir o valor da inscrição e da anuidade em virtude da junção de várias propriedades pela cooperativa. Mas este sistema deve ser organizado o mais rapidamente possível, preferencialmente com a ajuda de órgão públicos, já que o governo Brasileiro e a União Européia determinam prazos para a implantação da rastreabilidade no país.

\section{AGRADECIMENTOS E APRESENTAÇÃO}

Ao professor Dr. Marcos Aurélio Lopes, pela orientação e ajuda na confecção da monografia do curso de Especialização em Gestão da Informação no Agronegócio, da Universidade Federal de Juiz de Fora.

Parte da monografia de especialização em Gestão da Informação no Agronegócio do autor, Universidade Federal de Juiz de Fora (UFJF).

\section{REFERÊNCIAS}

BRASIL. Instrução Normativa N. 1/2002 de 09 de Janeiro de 2002. Institui o Sistema Brasileiro de Identificação e Certificação de Origem Bovina e Bubalina, SISBOV. Diário Oficial [da] União, Brasília, seção 1, p.6, 10/01/2002.

IBGE. Santa Catarina - Produto Interno Bruto 2002. Capturado em 11 de março de 2006. Online. Disponível em h t t p : / / w w w. i b g e. g o v. b r / e s t a d o s a t / temas.php?sigla=sc\&tema=pibmun2002\&titulo=Produto\%20Interno\% 20Bruto\%202002\%20

ICEPA - Instituto Cepa/SC. Levantamento Agropecuário Catarinense: resultados preliminares. Florianópolis. SC, 2004. CD-ROM.

LOMBARDI, M.C. Rastreabilidade: exigências sanitárias dos novos mercados. In: III CONGRESSO BRASILEIRO DE RAÇAS ZEBUÍNAS - A integração da cadeia produtiva, 10., 1998, Uberaba, MG. Anais... Uberaba: Associação Brasileira de Criadores de Zebu, 1998. p.90-94.

MACHADO J.G.C.; NANTES J.F.D. 2000a. A visão institucional do processo de rastreabilidade da carne bovina. Capturado em 15 mar. 2004. Online. Disponível na internet. http://www.agriculturadigital.org/agritec_2004/ congresso/Seg_e_Qual_Alim_Rastreab/A_Visão _Instit_Rastreabilid_Carne_Bovina.pdf.

MACHADO, J.G.C.; NANTES, J.F.D. 2000b. A rastreabilidade na cadeia da carne bovina. Capturado em 06 abr. 2004. Online. Disponível na internet http:// www.agriculturadigital.org/agritec_2004/congresso/ $\mathrm{S}$ e g $-\mathrm{e}-\mathrm{Q}$ u a l_A $\mathrm{l}$ i m_R a s t r e a b/ A_Rastreabilidade_na_Cadeia_Carne_Bovina.pdf.

SARTO, F.M. Análise dos impactos econômicos e sociais da implementação da rastreabilidade na pecuária bovina nacional. 2002. 56f. Monografia (Curso de graduação em Engenharia Agronômica) - Universidade de São Paulo, Escola Superior de Agricultura 'Luiz de Queiroz'.

WILLIAMSON, O.E. Transaction cost economics. In: SCHMALENSEE, R.; WILLING, R. Handbook of in industrial organization. London: Elsevier, 1999. V.1, Cap.3, p.136-182 